\title{
Degradation of trimethoprim by thermo-activated persulfate oxidation: Reaction kinetics and transformation mechanisms
}

\author{
Yuefei Ji ${ }^{\text {a1 }}$, Weiping Xie ${ }^{\mathrm{b} 1}$, Yan Fan ${ }^{\mathrm{a}}$, Yuanyuan $\mathrm{Shi}^{\mathrm{a}}$, Deyang $\mathrm{Kong}^{\mathrm{c}}$, Junhe $\mathrm{Lu}^{\text {a* }}$
}

${ }^{\text {a }}$ College of Resources and Environmental Science, Nanjing Agricultural University, Nanjing 210095, China

${ }^{\mathrm{b}}$ Environmental Monitoring Station of Yixing, Yixing, Jiangsu, 21400, China

${ }^{\mathrm{c}}$ Nanjing Institute of Environmental Sciences, Ministry of Environmental Protection of PRC, Nanjing 210042, China

* Corresponding author. Tel.: +86 25 84395164; fax: +86 2584395164 .

E-mail addresses: yuefeiji@njau.edu.cn (Y. Ji); jhlu@njau.edu.cn (J. Lu).

${ }^{1}$ The authors contributed equally to this research.

\begin{abstract}
Trimethoprim (TMP) is a dihydrofolate reductase inhibitor that is synergistically prescribed with sulfonamides to treat infectious disease in humans and animals. The widespread occurrence of TMP in natural environment may pose ecotoxicological risks to aquatic organisms and microalgae. In this work, we investigated the kinetics and mechanisms of TMP degradation by thermo-activated persulfate (PS) oxidation process in aqueous solution. Experimental results revealed that TMP could be effectively destructed at the temperature range of $50-65{ }^{\circ} \mathrm{C}$. Acidic $\mathrm{pH}$ facilitated the degradation of TMP. The pyrimidine moiety in TMP molecule was identified as the primary reactive site by comparison to substructural analogs. Solid phase extraction (SPE) coupled with liquid chromatography-electrospray ionization-triple quadrupole mass spectrometry (LC-ESI-MS/MS) was employed to identify the intermediate products. Thermo-activated PS oxidation of TMP produced several intermediates via hydroxylation and oxidation with $\alpha$-hydroxytrimethoprim (TMP-OH) and $\alpha$-ketotrimethoprim (TMP=O) being the major products. Water matrix affected TMP removal significantly, e.g., natural organic matter (NOM) and


bicarbonate $\left(\mathrm{HCO}_{3}^{-}\right)$inhibited the degradation while halides promoted it. Results from this study showed that thermo-activated PS oxidation could be an efficient approach to remove TMP from waters; however, the removal efficiency could be influenced by coexisting species.

Keywords: Antibiotics; Persulfate; Sulfate radical; Thermo activation; Trimethoprim

\section{Introduction}

Trimethoprim (5-(3,4,5-trimethoxy-benzyl) pyrimidine-2,4-diamine, TMP) (molecular structure provided in Fig. 1) is a dihydrofolate reductase (DHFR) inhibitor which prevents DNA replication by competing with dihydrofolate for binding to DHFR [1]. TMP is normally used synergistically with sulfamethoxazole at a ratio of 1:5 to treat infectious disease in humans [1]. It is also widely used as feed additives in livestock industry to enhance animal growth and improve feed efficiency [2]. Human body can only metabolize approximately $22.5 \%$ of TMP after ingestion [3]. The residual TMP and related metabolites are excreted via urine and feces, which ended up in municipal waste water [4,5]. Adsorption or microbial degradation of TMP was insignificant in conventional active sludge treatment process [6-8]. Therefore, TMP was frequently detected in wastewater treatment plant (WWTP) effluent, e.g., $0.12-0.16 \mu \mathrm{g} \mathrm{L}^{-1}$ in USA [9] and $68-81 \mathrm{ng}$

$\mathrm{L}^{-1}$ in Switzerland [10] were reported. As a result, effluent receiving waters are highly susceptible to contamination by TMP and other antibiotics [11]. For example, in Las Vegas Wash, TMP concentration of $80 \mathrm{ng} \mathrm{L}^{-1}$ was detected [11]. It was noticed that TMP could be degraded in nitrifying activated sludge [8,12-14], and ammonia oxidizing bacterial was found to play a critical role in its biotransformation [13,14]. However, since nitrification process is not prevalent in WWTPs in developing world, TMP and many other recalcitrant pharmaceuticals are released to surface waters [8]. For instance, TMP concentration of $100-140 \mu \mathrm{g} \mathrm{L} \mathrm{L}^{-1}$ was detected in Haihe River, China [15] and 7 - $44 \mathrm{ng} \mathrm{L}^{-1}$ in Mekong Delta, Vietnam [16].

(Fig. 1)

The widespread occurrence of TMP in natural waters poses risks to aquatic ecosystem because TMP was found to show ecotoxicological effects to aquatic organisms and inhibit the 
growth of freshwater microalgae [17,18]. It is essential to develop cost-effective and environmentally friendly treatment techniques to remove TMP and minimize the associated risks. Advanced oxidation processes (AOPs) have been studied to eliminate TMP, including photolysis [19], photo-Fenton [20], photocatalysis [21], permanganate [22,23], ferrate [24], ozonation [25,26], and chlorination [27]. For instance, ozonation and chlorination were found to be effective for eliminating TMP in drinking water treatment process [28,29]. However, some intrinsic drawbacks of AOPs may restrict their application. For example, ozonation of organic contaminants could produce carcinogenic bromate $\left(\mathrm{BrO}_{3}^{-}\right)$in the presence of bromide [30]. Generation of persistent/toxic products has been documented during ozonation/chlorination of TMP [26,27]. Permanganate and ferrate are effective to destruct TMP and reduce its toxicity [22-24]; however, their application is apparently limited by water matrices in real practice[22,24].

Recently, activated persulfate (peroxydisulfate, PS or peroxymonosulfate, PMS)) oxidation processes generating highly reactive sulfate radicals $\left(\mathrm{SO}_{4}^{-}\right)$have been showed to be effective to eliminate antibiotics in waters and sludge [31-36]. PS and PMS are chemically stable but can be activated by various approaches including heat, transit metal, UV light, base and sonolysis [37]. The resulting $\mathrm{SO}_{4}{ }^{--}$has a high standard redox potential $\left(E^{0}=2.5-3.1 \mathrm{~V}\right.$, depend on the $\left.\mathrm{pH}\right)[38]$, which is comparable to that of $\mathrm{HO} \bullet\left(E^{0}=1.9-2.7 \mathrm{~V}\right)$ [39]. Second-order rate constants between $\mathrm{SO}_{4}{ }^{--}$and organic compounds range from $10^{6}$ to $10^{9} \mathrm{M}^{-1} \mathrm{~s}^{-1}$ [40]. Therefore, $\mathrm{SO}_{4}{ }^{-}$can potentially mineralize a variety of organic compounds. Unlike $\mathrm{HO} \cdot \mathrm{SO}_{4}{ }^{-}$is more selective that reacts with organic compounds primarily through electron transfer mechanism [38,40]. This characteristic renders $\mathrm{SO}_{4}{ }^{-}$less scavenged by nontarget water constituents (e.g., natural organic matter, NOM), thus increasing its efficiency for the degradation of targeted contaminants [31]. Activated persulfate oxidation systems can be operated at $\mathrm{pHs}$ ranged from acidic to basic [41], which differed from Fenton and Fenton-like AOPs that are effective only at acidic pH [42]. In addition, PS and its final product, sulfate $\left(\mathrm{SO}_{4}{ }^{2-}\right)$, have minimal impacts on soil microorganisms after activation [43]. Therefore, $\mathrm{SO}_{4}{ }^{-}$-based AOPs have been applied for the treatment of wastewater and remediation of contaminated soil and groundwater as a promising in situ chemical oxidation (ISCO) technology [37,44]. More recently, Zhang et al. compared the degradation of TMP in synthetic human urine by UV/PS and $\mathrm{UV} / \mathrm{H}_{2} \mathrm{O}_{2}$ processes and demonstrated the former showed a better performance [33]. 
In the present study, we investigated the degradation of TMP by thermo activated PS process. The motivation was to explore a viable method to eliminate TMP in waters. Thermo activation was employed here because it is one of the simplest and most effective methods to activate PS to produce $\mathrm{SO}_{4}{ }^{--}$[37]. Although thermo activation requires additional cost for heating, no chemical activators are needed which prevent the formation of sludge or secondary contamination. In addition, recent development in coupling ISCO with in situ thermal remediation (ISTR) makes this technology an attractive option [45]. Therefore, thermo activation has been frequently employed to explore the reaction mechanisms between $\mathrm{SO}_{4}{ }^{-{ }^{-}}$and contaminant due to its simplicity and high efficiency.

In this work, kinetic studies were performed to gain insights into the influence factors (e.g., temperature and $\mathrm{pH}$ ) that affect TMP degradation. The reactive sites in TMP molecule susceptible to $\mathrm{SO}_{4}{ }^{-}$attack were determined by comparison with substructural analogs 2,4-diaminopyrimidine (DAPD) and 1,2,3-trimethoxybenzene (TMBz)). Solid phase extraction (SPE) combined with liquid chromatography-electrospray ionization-tandem mass spectrometry (LC-ESI-MS/MS) was employed to separate and identify various intermediate products. Based on the products identified, transformation pathways of TMP by thermo-activated PS oxidation were proposed. Finally, TMP degradation in synthesized river water and sea water were carried out to probe the effects of natural water matrices. Results obtained in this study may provide useful information for better understanding the degradation behavior of micropollutants (e.g., antibiotics) by activated persulfate oxidation processes.

\section{Materials and methods}

\subsection{Chemicals and materials}

Chemicals, suppliers, and purities are listed in the Text S1, Supplementary data.

\subsection{Experimental setup}

Batch kinetic studies were conducted in $33 \mathrm{~mL}$ screw-cap cylindrical glass vials with Teflon septa at predetermined temperature (i.e., 50 to $65{ }^{\circ} \mathrm{C}$ ) controlled by a thermostated water bath (Xianou Instrument Manufacture Co., Ltd, Nanjing). The temperature studied here fall into the range previously investigated by other researchers $[45,46]$. Prior to heat activation, appropriate 
volume of TMP or substructural analogs (i.e., 2,4-diaminopyrimidine, DAPD and 1,2,3-trimethoxybenzene, TMBz) stock solution $(150 \mu \mathrm{M})$ and PS stock solution $(100 \mathrm{mM})$ were transferred into the vials to achieve a total of $20 \mathrm{~mL}$ reaction solution with predetermined concentrations of TMP and PS (e.g., $30 \mu \mathrm{M}$ TMP and $2 \mathrm{mM}$ PS). Control experiments without PS were carried out under same conditions and showed no loss of target compounds. Initial $\mathrm{pH}$ was adjusted to desired value by $0.01 \mathrm{M} \mathrm{H}_{2} \mathrm{SO}_{4}$ or $\mathrm{NaOH}$. No buffer was used to avoid potential reactions between buffer species and $\mathrm{SO}_{4}{ }^{\circ}$. Synthesized river water (SRW) containing $5 \mathrm{mM}$ $\mathrm{HCO}_{3}{ }^{-}$and $2.5 \mathrm{mg} \mathrm{L}^{-1}$ Suwannee River fulvic acid (SRFA, as a representative of aquatic NOM), and synthesized sea water (SSW) containing $540 \mathrm{mM} \mathrm{Cl}^{-}$and $0.08 \mathrm{mM} \mathrm{Br}^{-}$were employed to assess the water matrix effects on thermo-activated PS oxidation of TMP. Sample aliquots $(0.5 \mathrm{~mL})$ were withdrawn intermittently and chilled in an ice bath for 10 min to stop the reaction and kept in a $4{ }^{\circ} \mathrm{C}$ refrigerator thereafter until further treatment and analysis. All the experiments were carried out in duplicates, and the data were averaged. The standard deviations were usually within 5-10\% unless otherwise stated. For products identification, $100 \mathrm{~mL} 136 \mu \mathrm{M}$ TMP and $9 \mathrm{mM}$ PS was allowed to reaction for $6 \mathrm{~h}$ under $50{ }^{\circ} \mathrm{C}$. After that, the reaction solution was chilled and then enriched by solid phase extraction.

\subsection{Analytical methods}

Concentrations of TMP and substructural analogs were determined by a Hitachi L-2000 high performance liquid chromatography equipped with an L-2455 diode array detector (HPLC-DAD). Detailed HPLC analytical parameters can be found in Table. S1, Supplementary data. Quantification of analytes was based on multipoint standard calibration. Reaction products were concentrated by solid phase extraction (SPE) using Waters Oasis hydrophilic-lipophilic balance (HLB) cartridges. Detailed experimental procedures are given in Text S2, Supplementary data. Reaction products were identified by liquid chromatography-electrospray ionization-triple quadrupole mass spectrometry (HPLC-ESI-MS/MS), consisting of an Agilent 1200 series HPLC and a G6410B triple quadrupole mass spectrometer. Separation was accomplished using an Agilent ZORBAX Eclipse Plus C18 column (3.5 $\mu \mathrm{m}, 150 \mathrm{~mm} \times 2.1 \mathrm{~mm}$ I.D.). The analytical details are presented in the Text S3, Supplementary data. Full scans as well as product ion scans were conducted to determine the quasi-molecular ions and elucidate the structures of major 
intermediate products. The time-dependent formation of products $\mathrm{m} / \mathrm{z}, 307,305$ and 323 were further determined using multiple reaction monitoring (MRM) mode with the optimized operating parameters showed in Table S2, Supplementary data. Instrument control, data acquisition and processing were performed using the associated Agilent Mass Hunter Qualitative analysis software (version B.04.00). Solution pH was measured by a combined glass electrode (E-201-C, Leici) connected to a PHS-3CW microprocessor $\mathrm{pH} / \mathrm{mV}$ meter (BANTE instrument).

\section{Results and discussion}

\subsection{Reaction kinetics}

Increasing the temperature facilitates the activation of PS and formation of $\mathrm{SO}_{4}{ }^{-}$, which in turn favors the degradation of contaminants in thermo-activated PS process as evidenced by Fig. 2. As seen, removal of TMP increased from 57.2 to $100 \%$ after 480 min reaction as the temperature increased from 50 to $65{ }^{\circ} \mathrm{C}$. No loss of TMP was observed in the absence of PS or at ambient temperature (data not shown), suggesting TMP was thermally stable and the degradation was primarily due to the reactions with radicals (e.g., $\mathrm{SO}_{4}{ }^{\circ}$ ) generated by thermo-activated PS.

The degradation of TMP can be fitted by pseudo-first-order kinetics model described by following equation (Eq. (1)).

$$
-\frac{\mathrm{d}[\mathrm{TMP}]}{\mathrm{d} t}=k_{o b s}[\mathrm{TMP}]
$$

Where $k_{\text {obs }}$ is the pseudo-first-order rate constant, [TMP] is the concentration of TMP at reaction time $t$. The $k_{\mathrm{obs}}$ value can be obtained by linear regression of plot of $\ln \left([\mathrm{TMP}]_{t} /[\mathrm{TMP}]_{0}\right)$ versus $t$. The $k_{\text {obs }}$ value increased by 25 -fold when the temperature was elevated from 50 to $65{ }^{\circ} \mathrm{C}$. Correspondingly, half-life time of TMP was reduced from 348.8 to $18.4 \mathrm{~min}$.

The temperature dependency of $k_{\text {obs }}$ was further evaluated by Arrhenius equation (Eq. (2)) to determine the apparent activation energy.

$$
\ln k_{\mathrm{obs}}=\ln \mathrm{A}-\frac{E_{\mathrm{a}}}{R T}
$$

Where $\mathrm{A}$ is the pre-exponential factor, $E_{\mathrm{a}}$ is the apparent activation energy, $R$ is the universal gas constant $\left(8.314 \mathrm{~J} \mathrm{~mol}^{-1} \mathrm{~K}^{-1}\right)$, and $T$ is the absolute temperature. Fig. S1 of Supplementary data showed a linear relationship between $\ln k_{\text {obs }}$ and $1 / T$, suggesting the relationship obeys Arrhenius 
equation. The $E_{\mathrm{a}}$ was determined to be $177.8 \mathrm{~kJ} \mathrm{~mol}^{-1}$ by fitting the experimental data to Eq. (2). Such a value is slightly higher than that of other contaminates previously reported, e.g., $108 \pm 3 \mathrm{~kJ}$ $\mathrm{mol}^{-1}$ for trichloroethene [45], $166.7 \pm 0.8 \mathrm{~kJ} \mathrm{~mol}^{-1}$ for diuron [46], and $141 \mathrm{~kJ} \mathrm{~mol}^{-1}$ for atrazine [47]. This discrepancy reflects the difference in molecular structures and the susceptibility to sulfate radical oxidation of these compounds.

(Fig. 2)

pH plays a complex role in thermo-activated PS oxidation of contaminants due to its ability to influence the formation and transformation of $\mathrm{SO}_{4}{ }^{-}$as well as to alter the speciation of contaminants $[48,49]$. Fig. 3 shows the $k_{\text {obs }}$ value of TMP degradation increased with decreasing $\mathrm{pH}$, indicating acidic condition favors thermo-activated PS oxidation of TMP. This is because acidic condition might facilitate the electrostatic interactions between $\mathrm{SO}_{4}{ }^{-}$and protonated pyrimidine ring ( $\mathrm{p} K_{\mathrm{a} 1}=3.2, \mathrm{p} K_{\mathrm{a} 2}=7.1$, see Fig. 1$)$ [33]. This conclusion was corroborated by the finding that pyrimidine ring was the primary reactive site for $\mathrm{SO}_{4}{ }^{-}$attack (see discussion later). Moreover, redox potential of $\mathrm{SO}_{4}{ }^{--}$was higher at acidic $\mathrm{pH}$ according to Nernstian equation, which may partly contribute to the higher $k_{\mathrm{obs}}$ as well. Compared to $\mathrm{pH}=3.0$ and 7.0 , the slightly low $k_{\mathrm{obs}}$ at $\mathrm{pH} 5.0$ is somewhat unexpected, and might be ascribed to the acid-catalyzed PS decomposition, which depleted PS without producing radicals [48].

Under basic condition, $\mathrm{SO}_{4}{ }^{-}$can be transformed to $\mathrm{HO} \bullet$ by reaction with hydroxyl ion (Eq. (3)) [50].

$\mathrm{SO}_{4}{ }^{--}+\mathrm{OH}^{-} \rightarrow \mathrm{SO}_{4}^{2-}+\mathrm{HO} \cdot$

Thus, $\mathrm{SO}_{4}{ }^{-}$concentration decreases while the $\mathrm{HO} \bullet$ concentration increases with increasing $\mathrm{pH}$ [51,52]. The redox potential of $\mathrm{HO} \bullet$ is lower than that of $\mathrm{SO}_{4}{ }^{-}$at basic $\mathrm{pH}[38]$, which may partly explained the decreased $k_{\text {obs }}$ at $\mathrm{pH} 9.0$ and 10.5 (Fig. 2). It is well-known that reaction mechanisms of $\mathrm{SO}_{4}{ }^{-}$- differ from that of $\mathrm{HO} \bullet$ because $\mathrm{SO}_{4}{ }^{-}$reacts with organic compounds primarily through electron transfer $[38,40]$, whereas $\mathrm{HO} \bullet$ reacts preferentially via addition to $\mathrm{C}=\mathrm{C}$ double bonds and abstracting $\mathrm{H}$ from $\mathrm{C}-\mathrm{H}, \mathrm{N}-\mathrm{H}$, or $\mathrm{O}-\mathrm{H}$ bonds [39,42]. Dodd et al. suggested that the trimethoxybenzene group of TMP molecule was the reactive site for HO• attack [27]. The different reaction mechanisms between $\mathrm{SO}_{4}{ }^{-}$and $\mathrm{HO} \cdot$ mediated oxidation might also contribute to the 
discrepancy in $k_{\mathrm{obs}}$ at acidic and basic $\mathrm{pH}$. The higher $k_{\mathrm{obs}}$ at $\mathrm{pH} 10.5$ compared with $\mathrm{pH} 9.0$ was likely a result of alkaline-catalyzed PS decomposition, which produced more reactive radicals such as $\mathrm{SO}_{4}{ }^{-\bullet}$ and $\mathrm{O}_{2}{ }^{-}[53]$.

(Fig. 3)

\subsection{Second-order-rate constants}

$\mathrm{SO}_{4}{ }^{-}$and $\mathrm{HO} \cdot$ have been demonstrated to be the predominant oxidizing species involved in thermo-activated PS process, and their importance was pH-dependent [50-52]. Data presented in Table 1 shows that the second-order-rate constants for reactions between TMP and $\mathrm{SO}_{4}{ }^{-} / \mathrm{HO} \cdot$ were near diffusion controlled limit (i.e., $k_{\text {diff }}=1.1 \times 10^{10} \mathrm{M}^{-1} \mathrm{~s}^{-1}$ ) [54], supporting the effective oxidation of TMP by thermo-activated PS process (see Fig. 2). These data also imply that HO• and $\mathrm{SO}_{4}{ }^{-}$-based AOPs can be applied to treat TMP contaminated waters in engineering utilities. However, the second-order-rate constant of $\mathrm{SO}_{4}{ }^{-}$is slightly lower than that of $\mathrm{HO} \cdot$, plausibly because $\mathrm{SO}_{4}{ }^{-}$is more selective $[38,40]$.

\section{(Table 1)}

With regards to the other reactive oxidizing species (e.g., $\mathrm{O}_{3}$ and $\mathrm{HOCl}$ ), their second-order-rate constants are generally lower than that of $\mathrm{SO}_{4}{ }^{--}$and $\mathrm{HO} \cdot$. However, oxidizing species with less reactivity are less likely scavenged by nontarget water constituents such as NOM and bicarbonate, hence, reaching higher steady-state concentrations. Therefore, less reactive oxidizing species may also induce the degradation of TMP as well as highly reactive oxidizing species, and effective oxidation of TMP by permanganate [22,23], ferrate [24], ozone [25,26] and free chlorine [27] has previously been documented.

\subsection{Reactive sites}

In order to determine the reactive sites in TMP molecule preferentially attacked by $\mathrm{SO}_{4}{ }^{-*}$, the degradation of TMP was compared with its substructural analogs including DAPD and TMBz (Fig. 4). As seen, the $k_{\mathrm{obs}}$ of TMP was slightly higher than that of TMBz but was markedly lower than 
that of DAPD, suggesting DAPD moiety was the primary reactive site for $\mathrm{SO}_{4}{ }^{--}$attack; whereas TMBz moiety was relatively inert. Previous studies have identified the DAPD moiety as the active site for singlet oxygen $\left({ }^{1} \mathrm{O}_{2}\right)[19]$, permanganate $\left(\mathrm{KMnO}_{4}\right)$ [22], and carbonate radical $\left(\mathrm{CO}_{3}{ }^{\circ}\right)[33]$, whereas TMBz moiety being reactive site for $\mathrm{HO} \cdot[25]$ and free chlorine $(\mathrm{HOCl})$ [27]. These discrepancies reflect the intrinsic difference in the reactivity of various radical/oxidants and their reaction mechanisms. The high reactivity of pyrimidine ring toward $\mathrm{SO}_{4}{ }^{--}$was consistent with a previous study reporting the formation of $\mathrm{SO}_{4}{ }^{-}$adduct or radical cation during $\mathrm{SO}_{4}{ }^{-}$attack [55].

\section{(Fig. 4)}

\subsection{Reaction products and evolution patterns}

Reaction products generated during thermo-activated PS oxidation of TMP were identified by SPE-LC-MS/MS technique. Positive full scan mass spectrum of SPE-enriched sample revealed five products with $\mathrm{m} / \mathrm{z}$ of $305,307,323,323$, and 323, respectively (data not shown). Products $\mathrm{m} / \mathrm{z}$ 307 and 305 were identified as $\alpha$-hydroxytrimethoprim (TMP-OH) and $\alpha$-ketotrimethoprim (TMP=O), respectively, based on product ion mass spectra (Fig. S4 to S7, Supplementary data). The fragmentation patterns of $\mathrm{TMP}-\mathrm{OH}$ and $\mathrm{TMP}=\mathrm{O}$ were consistent with those proposed by $\mathrm{Hu}$ et al. [23], which further supported their structural assignment. These two compounds have also been identified as transformation products of TMP during photolysis [19], photo-Fenton [20], photocatalysis [21], ferrate [24], permanganate [23] and UV/PS treatment [33].

\section{(Fig. 5)}

Interestingly, three isomers with $\mathrm{m} / \mathrm{z} 323$ were detected by chromatographic separation as displayed in Fig. 5. These isomers have not previously been reported in $\mathrm{SO}_{4}{ }^{-}-$based oxidation of TMP [33]. The additional 32 amu relative to TMP $(\mathrm{m} / \mathrm{z} 291)$ suggested that the isomers should be di-hydroxylated TMP. Product ion scan mass spectra of $\mathrm{m} / \mathrm{z} 323$ showed the formation of fragmentation ion $\mathrm{m} / z 123$ or $\mathrm{m} / \mathrm{z} 110$, which were corresponding to the characteristic fragments of protonated TMP containing pyrimidine group (Fig. S2 and S3, Supplementary data) [12,23]. These findings indicated that di-hydroxylation (i.e., $\mathrm{m} / \mathrm{z} 323$ ) should occur at bridging methylene and 
TMBz moiety. The lack of fragmentation ion $m / z 181$ (i.e., 1,2,3-trimethoxytoluene) in product ion scan mass spectra of $m / z 323$ further supported that TMBz moiety was substituted by at least one hydroxyl group. Structural elucidations of these isomers were further performed according to corresponding fragmentation patterns (Fig. S8 to S10, Supplementary data). Of them, $m / z$ 323-1 was assigned to be di-hydroxylated TMP with hydroxylation both occurred at TMBz ring. This assignment was further supported by the fact that $m / z$ 323-1 was eluted out first on C18 reverse phase column $(\mathrm{RT}=7.2 \mathrm{~min})$ and its MS differed from that of $\mathrm{m} / \mathrm{z} 323-2(\mathrm{RT}=9.0 \mathrm{~min})$ and $\mathrm{m} / \mathrm{z}$ 323-3 (RT = $17.8 \mathrm{~min}$ ). Interestingly, $\mathrm{m} / \mathrm{z} 323-2$ and 323-3 exhibited the same MS; however, $\mathrm{m} / \mathrm{z}$ 323-3 was eluted much slower than $\mathrm{m} / \mathrm{z}$ 323-2. Such a phenomenon has previously been reported for the degradation products of bezafibrate and atenolol in photocatalysis, and was ascribed to the formation of intramolecular hydrogen bond [56,57]. Intramolecular hydrogen bond can decrease polarity of the molecule [56,57]. Therefore, molecular structure of $\mathrm{m} / \mathrm{z}$ 323-3 was determined as one hydroxylation occurred at bridging methylene and the other occurred at 2 position of TMBz (see Fig. 1 for positions labeled with numbers) because hydroxylation at these positions were favorable for formation of intramolecular hydrogen bond. Consequently, molecular structure of $\mathrm{m} / \mathrm{z}$ 323-2 was identified with one hydroxylation occurred at bridging methylene and the other occurred at 6 position of TMBz.

The evolution of products over the reaction course was further quantitatively examined by LC-MS/MS analysis under MRM mode. As showed in Fig. 6a, TMP-OH reached maximum rapidly (i.e., $30 \mathrm{~min}$ ) after the reaction was initialized, and decayed gradually thereafter following the disappearance of TMP. TMP=O exhibited an identical evolution profile as TMP-OH except that it reached maximum slightly later (i.e., $45 \mathrm{~min}$ ). This tendency implied that $\mathrm{TMP}=\mathrm{O}$ was likely derived from TMP-OH. Fig. 6b displays the evolution profiles of three isomers with $\mathrm{m} / \mathrm{z}$ 323. Product $\mathrm{m} / \mathrm{z}, 323-1$ and 323-2 reached maximum concentrations between 30 to $60 \mathrm{~min}$ and then diminished quickly as the reaction proceeded. Differently, product $m / z$ 323-3 approached maximum much latter and decayed much slowly. This finding is reasonable considering the available site for $\mathrm{SO}_{4}{ }^{-}$further attack in $\mathrm{m} / z$ 323-3 is the 6 position of $\mathrm{TMBz}$, which was relatively unfavored due to steric hindrance effect. 
Accurate quantification of the intermediate products seemed to be impossible due to the lack of authentic standards. However, full scan mass spectrum showed that the peak intensity of TMP-OH and TMP $=\mathrm{O}$ was substantially higher than that of di-hydroxylation isomers (data not shown), suggesting that they are the major products of TMP degradation. This conclusion was supported by Zhang et al. that TMP-OH and TMP=O were the only products identified in UV activated PS oxidation of TMP in synthetic human urine [33]. It should be noted that both TMP, TMP-OH, TMP $=\mathrm{O}$ and isomers were completely destructed after 240 min, suggesting the cleavage of the rings or even mineralization of TMP.

\subsection{Transformation mechanisms and pathways}

Based on the products identified and the reactive sites determined, TMP transformation pathway in thermo-activated PS process was temporarily proposed in Fig. 7. The reaction was initialized by the attack of $\mathrm{SO}_{4}{ }^{--}$on pyrimidine ring, the reactive site of TMP, leading to the formation of a radical cation via electron transfer mechanism $[38,40]$. Formation of pyrimidine radical cation has previously been observed by spin trapping-electron paramagnetic resonance (EPR) analysis [55]. The radical cation was unstable and ready to loss of a proton from bridging methylene carbon, resulting in a carbon-centered radical which was stabilized by the adjacent pyrimidine and trimethoxybenzene ring through resonance [24]. The carbon-centered radical reacted with the dissolved oxygen quickly, producing a peroxyl radical that decayed via bimolecular self-termination reaction to form a tetroxide species [19]. It is well-accepted that tetroxides can undergo unimolecular decomposition to form alcohols (e.g., TMP-OH) and ketones (e.g., TMP=O), which were detected in this work [19]. Detailed mechanisms for TMP-OH and $\mathrm{TMP}=\mathrm{O}$ formation were provided in Fig. S11, Supplementary data. It should be noted that the carbon-centered radical can plausibly be produced by direct $\mathrm{SO}_{4}{ }^{-}$attack at bridging methylene via H-abstract mechanism; however, such reaction appeared to be less likely in comparison to electron transfer mechanism [38], and pyrimidine ring was confirmed to be the reactive site for $\mathrm{SO}_{4}{ }^{\circ}$ attack (Fig. 4). Formation of TMP-OH was also likely derived from the direct attack of carbon-centered radical by $\mathrm{HO} \cdot$ generated by reactions between $\mathrm{SO}_{4}{ }^{-{ }^{-}}$and $\mathrm{H}_{2} \mathrm{O} / \mathrm{OH}^{-}$. Further oxidation of TMP-OH by $\mathrm{SO}_{4}{ }^{-}$and/or $\mathrm{HO} \bullet$ also likely give rise to $\mathrm{TMP}=\mathrm{O}$. 
(Fig. 7)

Trimethoxybenzene ring manifested low reactivity for $\mathrm{SO}_{4}{ }^{*}$ attack. Nevertheless, the detection of three isomers suggested that such reaction could occur. It is well-documented that $\mathrm{SO}_{4}{ }^{--}$attack on benzene ring leads to the formation of a radical cation through electron-transfer mechanism, which undergoes hydrolysis to produce a hydroxycyclohexadienyl radical (HCHD), the same intermediate generated upon reaction between $\mathrm{HO} \bullet$ and benzene $[58,59]$. Hydroxylation products were consequently formed by sequential $\mathrm{O}_{2}$ adduct followed by $\mathrm{HO}_{2}{ }^{*}$ elimination $[58,59]$. Therefore, the formation of $\mathrm{m} / \mathrm{z}$ 323-1 was the result of two-step hydroxylation by $\mathrm{SO}_{4}{ }^{-{ }^{-}}$and/or $\mathrm{HO} \cdot$. On the other hand, the generation of $\mathrm{m} / 2,323-2$ and 323-3 was originated from the further hydroxylation of TMP-OH ( $\mathrm{m} / \mathrm{z}$ 307) (Fig. 7.).

\subsection{Effects of water matrices}

TMP degradation by AOPs can apparently be influenced by water matrices [20-22]. To gain insights into the effects of water matrices, TMP degradation was performed in synthesized river water (SRW) and sea water (SSW). Fig. 8 shows that SRW, containing medium level of NOM and $\mathrm{HCO}_{3}^{-}$, suppressed TMP degradation. This result could be attributed to the $\mathrm{SO}_{4}{ }^{--}$scavenging effects of $\mathrm{NOM}$ and $\mathrm{HCO}_{3}^{-} \cdot \mathrm{HCO}_{3}^{-}$can scavenge $\mathrm{SO}_{4}^{-} / \mathrm{HO} \cdot$ to generate carbonate radical $\left(\mathrm{HCO}_{3}{ }^{\circ} / \mathrm{CO}_{3}{ }^{-}\right)($Eqs. $(4-5))[60,61]$.

$$
\begin{aligned}
& \mathrm{SO}_{4}^{\bullet-}+\mathrm{HCO}_{3}^{-} \rightarrow \mathrm{SO}_{4}^{2-}+\mathrm{H}^{+}+\mathrm{HCO}_{3}^{\bullet}, k=1.6 \times 10^{6} \mathrm{M}^{-1} \mathrm{~S}^{-1} \\
& \mathrm{HO} \bullet+\mathrm{HCO}_{3}^{-} \rightarrow \mathrm{H}_{2} \mathrm{O}+\mathrm{CO}_{3}^{\bullet-}, k=8.5 \times 10^{6} \mathrm{M}^{-1} \mathrm{~s}^{-1}
\end{aligned}
$$

Carbonate radical is less reactive and only reacts with electron-rich compounds (e.g., phenols and anilines) at fairly high rate [62-64]. In the present study, the presence of $\mathrm{HCO}_{3}{ }^{-}$manifested an inhibitory effect plausibly because producing of $\mathrm{HCO}_{3}{ }^{\circ} / \mathrm{CO}_{3}{ }^{--}$could not offset the scavenging of $\mathrm{SO}_{4}{ }^{-} / \mathrm{HO} \cdot$. In addition, electron-rich moieties (ERMs) in NOM molecule (e.g., phenolic) could compete with TMP for reaction with $\mathrm{SO}_{4}^{*} / \mathrm{HO} \bullet$ [65]. Our recent studies demonstrated the inhibitory effect of $\mathrm{NOM}$ on $\mathrm{SO}_{4}{ }^{--}$-based oxidation of atrazine and sulfonamides [34,35,47]. 
In contrast, the degradation of TMP in SSW matrix was appreciably enhanced (Fig. 8). This can be interpreted by the formation of reactive halogen species (RHS) due to the reactions between $\mathrm{SO}_{4}{ }^{-}$and $\mathrm{Cl}^{-} / \mathrm{Br}^{-}$(Eqs (6)-(14)) $[60,61,66,67]$.

$$
\begin{aligned}
& \mathrm{SO}_{4}^{\bullet-}+\mathrm{X}^{-} \rightarrow \mathrm{SO}_{4}^{2-}+\mathrm{X}^{\bullet} \\
& \mathrm{HO} \bullet+\mathrm{X}^{-} \rightarrow \mathrm{XOH}^{\bullet-} \\
& \mathrm{XOH}^{\bullet-}+\mathrm{H}^{+} \rightarrow \mathrm{X}^{\bullet}+\mathrm{H}_{2} \mathrm{O} \\
& \mathrm{XOH}^{\bullet-}+\mathrm{X}^{-} \rightarrow \mathrm{X}_{2}^{\bullet-}+\mathrm{OH}^{-} \\
& \mathrm{X} \bullet+\mathrm{X}^{-} \rightarrow \mathrm{X}_{2}^{\bullet-} \\
& \mathrm{X} \bullet+\mathrm{X} \bullet \rightarrow \mathrm{X}_{2} \\
& \mathrm{X}_{2}^{\bullet-}+\mathrm{X}_{\bullet} \rightarrow \mathrm{X}_{2}+\mathrm{X}^{-} \\
& \mathrm{X}_{2}^{\bullet-}+\mathrm{X}_{2}^{\bullet-} \rightarrow \mathrm{X}_{2}+2 \mathrm{X}^{-} \\
& \mathrm{X}_{2}+\mathrm{H}_{2} \mathrm{O} \rightarrow \mathrm{HXO}+\mathrm{H}^{+}+\mathrm{X}^{-}
\end{aligned}
$$

Although these RHS, including both radicals (e.g., $\mathrm{X}^{*}, \mathrm{X}_{2}{ }^{--}$and $\mathrm{XOH}^{*}$ ) and free halogen (e.g., $\mathrm{X}_{2}$ and HOX), are moderate reactive species, they can react with electron-rich compounds rapidly $[59,66]$. In addition, RHS concentration could be several-orders of magnitude higher than that of $\mathrm{SO}_{4}{ }^{-}[66,68]$. Thus, when electron-rich compounds are present (e.g., phenols), the presence of halogen ions may exhibit promoting effects $[59,66]$. In addition, TMBz moiety within TMP molecule has been reported to be HOCl-reactive [27]. Therefore, the elevated degradation of TMP might be resulted from the attack of RHS on TMBz moiety. However, RHS reactions with organic compounds can lead to the formation of toxic and carcinogenic halogenated compounds [59, 68-70], and generation of chlorinated intermediates has been reported during chlorination of TMP [27]. Therefore, the formation of halogenated TMP in the SSW matrix by thermo-activated PS oxidation is of concern and warrants further study.

\section{Conclusions}


TMP has been frequently detected in WWTP effluents, surface waters and sediments. The widespread occurrence of TMP may pose ecotoxicological risks to aquatic ecosystem. This study suggests thermo-activated PS oxidation process is effective to eliminate TMP in waters. However, the removal efficiency is apparently influenced by operational conditions (e.g., temperature and $\mathrm{pH})$ and water matrix. $\mathrm{NOM}$ and $\mathrm{HCO}_{3}{ }^{-}$at concentrations typically encountered in natural waters, could inhibit TMP degradation. In contrast, halides (i.e., $\mathrm{Cl}^{-}$and $\mathrm{Br}^{-}$) at sea water levels remarkably enhanced the TMP destruction. However, the formation of potential chlorinated intermediates should be considered.

Hydroxylation and oxidation were found to be the major reaction pathways responsible for TMP's degradation. However, structural modification occurred primarily at bridging methylene and trimethoxybenzene moiety with $\alpha$-hydroxytrimethoprim and $\alpha$-ketotrimethoprim being the major intermediate products. It should be noted that the antimicrobial activity of TMP was mainly originated from pyrimidine moiety because it resembles part of the structure of 7,8-dihydrofolic acid. The intermediates identified herein contained the pyrimidine group without modification, implying that the antimicrobial activity might be largely reserved. Further studies assessing the ecotoxicological effects of these intermediate products are highly desirable before applying thermo-activated PS oxidation process for practical environmental remediation.

\section{Acknowledgements}

This work was supported by China Postdoctoral Research Funds (2015M570454), Jiangsu Planned Projects for Postdoctoral Research Funds (1402013A), Fundamental Research Funds for the Central Universities (KYZ201407), and the Priority Academic Program Development (PAPD) of Jiangsu Higher Education Institute. The content of the paper does not necessarily represent the views of the funding agencies.

\section{Appendix A. Supplementary Data}

Supplementary data associated with this article can be found, in the online version.

\section{References}

[1] C. Walsh, Antibiotics: action, origins, resistance, ASM Press, Washington, DC, 2003. 
[2] A. Boxall, D. Kolpin, B. Holling-Sorensen, J. Tolls, Are veterinary medicines causing environmental risks?, Environ. Sci. Technol. 37 (2003) 287A-294A.

[3] J. Rieder, Metabolism and techniques for assay of trimethoprim and sulfamethoxazole, J. Infect. Dis. 1973 S567-S573.

[4] K. Kümmerer, Antibiotics in the aquatic environment-a review-Part I, Chemosphere 75 (2009) 417-434.

[5] S.R. Hughes, P. Kay, L.E. Brown, Global synthesis and critical evalution of pharmaceutical data sets collected from river system, Environ. Sci. Technol. 47(2) (2012) 661-677

[6] A. Göbel, A. Thomsen, C.S. Mcardell, A. Joss, W. Giger, Occurrence and sorption behavior of sulfonamides, macrolides, and trimethoprim in activated sludge treatment, Environ. Sci. Technol. 39 (2005) 3981-3989.

[7] R.H. Lindberg, U. Olofsson, P. Rendahl, M.I. Johansson, M. Tysklind, B.A.V. Andersson, Behavior of fluoroquinolones and trimethoprim during mechanical, chemical, and active sludge treatment of sewage water and digestion of sludge, Environ. Sci. Technol. 40 (2006) 1042-1048.

[8] S. Pérez, P. Eichhorn, D.S. Aga, Evaluating the biodegradability of sulfamethazine, sulfamethoxazole, sulfathiazole, and trimethoprim at different stages of sewage treatment, Environ. Toxicol. Chem. 24(6) (2005) 1361-1367.

[9] A.L. Batt, D.S. Aga, Simultaneous analysis of multiple classes of antibiotics by ion trap LC/MS/MS for assessing surface water and groundwater contamination, Anal. Chem. 77 (2005) 2940-2947.

[10] A. Göbel, C.S. McArdell, M. J.-F. Suter, W. Giger, Trace determination of macrolide and sulfonamide antimicrobials, a human sulfonamide metabolite, and trimethoprim in wastewater using liquid chromatography coupled to electrospray tandem mass spectrometry, Anal. Chem. 76 (2004) 4756-4764.

[11] B.J. Vanderford, S.A. Snyder, Analysis of pharmaceuticals in water by isotope dilution liquid chromatography/tandem mass spectrometry, Environ. Sci. Technol. 40 (2006)7312-7320.

[12] P. Eichhorn, P.L. Ferguson, S. Pérez, D.S. Aga, Application of ion trap-MS with H/D exchange and QqTOF-MS in the identification of microbial degradates of trimethoprim in nitrifying activated sludge, Anal. Chem. 77 (2005) 4176-4184.

[13] A.L. Batt, S. Kim, D.S. Aga, Enhanced biodegradation of iopromide and trimethoprim in 
nitrifying activated sludge, Environ. Sci. Technol. 40 (2006) 7367-7373.

[14] W.O. Khunjar, S.A. Mackintosh, J. Skotnicka-Pitak, S. Baik, D.S. Aga, N.G. Love, Elucidating the relative roles of ammonia oxidizing and heterotrophic bacteria during the biotransformation of 17 $\alpha$-Ethinylestradiol and trimethoprim, Environ. Sci. Technol. 45 (2011) $3605-3612$.

[15] Y. Luo, L. Xu, M. Rysz, Y. Wang, H. Zhang, P.J.J. Alvarez, Occurrence and transport of tetracycline, sulfonamide, quinolone, and macrolide antibiotics in the Haihe River basin, China, Environ. Sci. Technol. 45 (2011) 1827-1833.

[16] S. Managaki, A. Murata, T. Takada, B. Cach Tuyen, N.H. Chiem, Distribution of macrolines, sulfonamides, and trimethoprim in tropical waters: ubiquitous occurrence of veterinary antibiotics in the Mekong Delta, Environ. Sci. Technol. 41 (2007) 8004-8010.

[17] M. De Liguoro, V. Di Leva, M. Dalla Bona, R. Merlanti, G. Caporale, G. Radaelli, Sublethal effects of trimethoprim on four freshwater organisms, Ecotoxicol. Environ. Safety 82 (2012) $114-121$

[18] B. Kolar, L. Arnuš, B. Jeretin, A. Gutmaher, D. Drobne, M. Kos Durjava, The toxic effect of oxytetracycline and trimethoprim in the aquatic environment, Chemosphere 115 (2014) 75-80.

[19] X. Luo, Z. Zheng, J. Greaves, W.J. Cooper, W. Song, Trimethoprim: kinetics and mechanistic considerations in photochemical environmental fate and AOP treatment, Water Res. 46 (2012)1327-1336.

[20] I. Michael, H. Hapeshi, V. Osorio, S. Pérez, M. Petrović, A. Zapata, S. Malato, D. Barceló, D. Fatta-Kasinos, Solar photocatalytic treatment of trimethoprim in four environmental matrices at a pilot scale: transformation products and ecotoxicity evaluation, Sci. Total Environ. 430 (2012) $167-173$

[21] C. Sirtori, A. Agüera, W. Gernjak, S. Malato, Effect of water-matrix composition on trimethoprim solar photodegradation kinetics and pathways, Water Res, 44 (2010) 2735-2744.

[22] L. Hu, H.M. Martin, T.J. Strathmann, Oxidation kinetics of antibiotics during water treatment with potassium permanganate, Environ. Sci. Technol. 44 (2010) 6416-6422.

[23] L. Hu, A.M. Stemig, K.H. Wammer, T.J. Strathmann, Oxidation of antibiotics during water treatment with potassium permanganate: reaction pathways and deactivation, Environ. Sci. Technol. 45 (2011) 3635-3642. 
[24] G.A.K. Anquandah, V.K. Sharma, D. Andrew Knight, S. Rani Batchu, P.R. Gardinali, Oxidation of trimethoprim by ferrate (VI): kinetics, products, and antibacterial activity, Environ. Sci. Technol. 5 (2011) 10575-10581.

[25] M.C. Dodd, M.-O. Buffle, U. von Gunten, Oxidation of antibacterial molecules by aqueous ozone: moiety-specific reaction kinetics and application to ozone-based wastewater treatment, Environ. Sci. Technol. 40 (2006) 1969-1977.

[26] J. Radjenović, M. Godehardt, M. Petrović, A. Hein, M. Farré, M. Jekel, D. Barceló, Evidencing generation of persistent ozonation products of antibiotics roxithromycin and trimethoprim, Environ. Sci. Technol. 43 (2009) 6808-6815.

[27] M.C. Dodd, C.-H. Huang, Aqueous chlorination of the antibacterial agent trimethoprim: reaction kinetics and pathways, Water Res. 41, (2007) 647-655.

[28] P. Westerhoff, Y. Yoon, S. Snyder, E. Wert, Fate of endocrine-disruptor, pharmaceutical, and personal care product chemicals during simulated drinking water treatment processes, Environ. Sci. Technol. 39 (2005) 6649-6663.

[29] M.J. Benotti, R.A. Trenholm, B.J. Vanderford, J.C. Holady, B.D. Stanford, S.A. Snyder, Pharmaceuticals and endocrine disrupting compounds in U.S. drinking water, Environ. Sci. Technol. 43 (2009) 597-603.

[30] U. von Gunten, Ozonation of drinking water: Part II. Disinfection and by-product formation in presence of bromide, iodide or chlorine, Water Res. 37 (2003) 1469-1487.

[31] M. Mahdi Ahmed, S. Barbati, P. Doumenq, S. Chiron, Sulfate radical anion oxidation of diclofenac and sulfamethoxazole for water decontamination, Chem. Eng. J. 197 (2012) 440-447.

[32] Y. Ji, C. Ferronato, A. Salvador, X. Yang, J.-M. Chovelon, Degradation of ciprofloxacin and sulfamethoxazole by ferrous-activated persulfate: implications for remediation of groundwater contaminated by antibiotics, Sci. Total Environ. 472 (2014) 800-808.

[33] R. Zhang, P. Sun, T.H. Boyer, L. Zhao, C.-H. Huang, Degradation of pharmaceuticals and metabolite in synthetic human urine by UV, $\mathrm{UV} / \mathrm{H}_{2} \mathrm{O}_{2}$, and UV/PDS, Environ. Sci. Technol. 49 (2015) 3056-3066.

[34] Y. Fan, Y. Ji, D. Kong, J. Lu, Q. Zhou, Kinetic and mechanistic investigations of the degradation of sulfamethazine in heat-activated persulfate oxidation process, J. Hazard. Mater. 300 (2015) 39-47. 
[35] Y. Ji, Y. Fan, K. Liu, D. Kong, J. Lu, Thermo activated persulfate oxidation of antibiotic sulfamethoxazole and structurally related compounds, Water Res. 87 (2015) 1-9.

[36] N. Bilgin Oncu, N. Mercan, I. Akmehmet Balcioglu, The impact of ferrous iron/heat-activated persulfate treatment on waste sewage sludge constituents and sorbed antimicrobial micropollutants, Chem. Eng. J. 259 (2015) 972-980.

[37] A. Tsitonaki, B. Petri, M. Crimi, H. Mosbæk, R.L. Siegrist, P.L. Bjerg, In situ chemical oxidation of contaminated soil and groudwater using persulfate: A review, Crit. Rev. Environ. Sci. Technol. 40 (2010) 55-91.

[38] P. Neta, R.E. Huie, A.B. Ross, Rate constants for reactions of inorganic radicals in aqueous solution, J. Phys. Chem. Ref. Data 17(3) (1988) 1027-1284.

[39] G.V. Buxton, C.L. Greenstock, W.P. Helman, A.B. Ross, Critical review of rate constants for reactions of hydrated electrons hydrogen atoms and hydroxyl radicals $\left(\mathrm{OH} / \mathrm{O}^{*}\right)$ in aqueous solution, J. Phys. Chem. Ref. Data 17 (1988) 513-886.

[40] P. Neta, V. Madhavan, H. Zemel, R.W. Fessenden, Rate constants and mechanism of reaction of $\mathrm{SO}_{4}{ }^{--}$with aromatic compounds, J. Am. Chem. Soc. 99 (1977) 163-164.

[41] Y. Guan, J. Ma, X. Li, J. Fang, L. Chen, Influence of $\mathrm{pH}$ on the formation of sulfate and hydroxyl radicals in the UV/peroxymonosulfate system, Environ. Sci. Technol. 45 (2011) 9308-9314.

[42] J.J. Pignatello, E. Oliveros, A. MacKay, Advanced oxidation processes for organic contaminant destruction based on the Fenton reaction and related chemistry, Crit. Rev. Environ. Sci. Technol. 36 (2006) 1-84.

[43] A. Tsitonaki, B.F. Smets, P.L. Bjerg, Effects of heat-activated persulfate oxidation on soil microorganisms, Water Res. 42 (2008) 1013-1022.

[44] R.J. Watts, A.L. Teel, Treatment of contaminated soil and groundwater using ISCO, Pract. Period. Hazard. Toxic Radioact. Waste Manage. 10 (2006) 2-9.

[45] R.H. Waldemer, P.G. Tratnyek, R.L. Johnson, J.T. Nurmi, Oxidation of chlorinated ethenes by heat-activated persulfate: Kinetics and products, Environ. Sci. Technol. 41 (2007) 1010-1015.

[46] C. Tan, N. Gao, Y. Deng, N. An, J. Deng, Heat-activated persulfate oxidation of diuron in water, Chem. Eng. J. 203 (2012) 294-300.

[47] Y. Ji, C. Dong, D. Kong, J. Lu, Q. Zhou, Heat-activated persulfate oxidation of atrazine: 
implications for remediation of groundwater contaminated by herbicides, Chem. Eng. J. 263 (2015) $45-54$.

[48] I.M. Kolthoff, I.K. Miller, The chemistry of persulfate. I. The kinetics and mechanism of the decompostition of the persulfate ion in aqueous medium, J. Am. Chem. Soc. 73 (1951) 3055-3059. [49] L. Dogliotti, E. Hayon, Flash photolysis of persulfate ions in aqueous solutions. Study of the sulfate and ozonide radical anions, J.Phys. Chem. 71 (1967) 2511-2516.

[50] C. Liang, Z. Wang, C.J. Bruell, Influence of $\mathrm{pH}$ on persulfate oxidation of TCE at ambient temperatures, Chemosphere (66) 2007 106-113.

[51] D. Zhao, X. Liao, X. Yan, S.G. Huling, T. Chai, H. Tao, Effect and mechanism of persulfate activated by different methods for PAHs removal in soil, J. Hazard. Mater. 254-255 (2013) $228-235$

[52] G. Fang, D.D. Dionysiou, D. Zhou, Y. Wang, X. Zhu, J. Fan, L. Cang, Y. Wang, Transformation of polychlorinated biphenyls by persulfate at ambient temperature, Chemosphere 90 (2013) 1573-1580.

[53] O. Furman, A.L. Teel, R. Watts, Mechanism of base activation of persulfate, Environ. Sci. Technol. 44 (2010) 6423-6428.

[54] L. Wojnárovits, E. Takács, Structure dependence of the rate coefficients of hydroxyl radical + aromatic molecule reaction, Radiat. Phys. Chem. 87(2013) 82-87.

[55] K. Hildenbrand, G. Behrens, D. Schulte-Frohlinde, Comparison of the reaction of $\bullet \mathrm{OH}$ and of $\mathrm{SO}_{4}^{-\bullet}$ radicals with pyrimidine nucleosides. An electron spin resonances study in aqueous solution, J. Chem. Soc. Perkin Trans. II (1989) 283-289.

[56] D.A. Lambropoulou, M.D. Hernando, I.K. Konstantinou, E.M. Thurman, I. Ferrer, T.A. Albanis, A.R. Fernández-Alba, Identification of photocatalytic degradation products of bezafibrate in $\mathrm{TiO}_{2}$ aqueous suspensions by liquid and gas chromatography, J. Chromatogr. A 1183 (2008) $38-48$.

[57] J. Radjenović, C. Sirtori, M. Petrović, D. Barceló, S. Malato, Solar photocatalytic degradation of persistent pharmaceuticals at pilot-scale: kinetics and characterization of major intermediate products, Appl. Catal. B: Environ. 89 (2009) 255-264.

[58] G. Merga, C.T. Aravindakumar, B.S.M. Rao, Pulse radiolysis study of the reactions of $\mathrm{SO}_{4}{ }^{*-}$ with some substituted benzene in aqueous solution, J. Chem. Soc. Faraday Trans. 90(4) (1994) 
597-604.

[59] G.P. Anipsitakis, D.D. Dionysiou, M.A. Gonzalez, Cobalt-mediated activation of peroxymonosulfate and sulfate radical attack on phenolic compounds. Implications of chloride ions, Environ. Sci. Technol. 40 (2006) 1000-1007.

[60] C. Liang, Z. Wang, N. Mohanty, Influence of carbonate and chloride ions on persulfate oxidation of trichloroethylene at $20^{\circ} \mathrm{C}$, Sci. Total. Environ. 370 (2006) 271-277.

[61] L.R. Bennedsen, J. Muff, E.G. Søgaard, Influence of chloride and carbonates on the reactivity of activated persulfate, Chemosphere 86 (2012) 1092-1097.

[62] S. Canonica, T. Kohn, M. Mac, F.J. Real, J. Wirz, U. von Gunten, Photosensitizer method to determine rate constants for the reaction of carbonate radical with organic compounds, Environ. Sci. Technol. 39 (2005) 9182-9188.

[63] R.A. Larson, R.G. Zepp, Reactivity of the carbonate radical with aniline derivatives, Environ. Toxicol. Chem. 7 (1988) 265-274.

[64] J. Huang, S.A. Mabury, Steady-state concentrations of carbonate radicals in field waters, Environ. Toxicol. Chem. 19 (2000) 2181-2188.

[65] P.M. David Gara, G.N. Bosio, M.C. Gonzalez, N. Russo, M. del Carmen Michelini, R. Pis Diez, D.O. Mártire, A combined theoretical and experimental study on the oxidation of fulvic acid by the sulfate radical anion, Photochem. Photobiol. Sci. 8 (2009) 992-997.

[66] Y. Yang, J.J. Pignatello, J. Ma, W.A. Mitch, Comparison of halide impacts on the efficiency of contaminant degradation by sulfate and hydroxyl radical-based advanced oxidation processes (AOPs), Environ. Sci. Technol. 48 (2014) 2344-2351.

[67] J. Lu, J. Wu, Y. Ji, D. Kong, Transformation of bromide in thermos activated persulfate oxidation processes, Water Res. 78 (2015) 1-8.

[68] R. Yuan, Z. Wang, Y. Hu, B. Wang, S. Gao, Probing the radical chemistry in UV/persulfate-based saline wastewater treatment: kinetics modeling and byproducts identification, Chemosphere 109 (2014) 106-112.

[69] L. Xu, R. Yuan, Y. Guo, D. Xiao, Y. Gao, Z. Wang, J. Liu, Sulfate radical-induced degradation of 2,4,6-trichlorophenol: a de novo formation of chlorinated compounds, Chem. Eng. J. 217 (2013) 169-173.

[70] K. Liu, J. Lu, Y. Ji, Formation of brominated disinfection by-products and bromate in cobalt 
catalyzed peroxymonosulfate oxidation of phenol, Water Res. 84 (2015) 1-7. 
Table 1. Measured second-order-rate constants for reactions between TMP and various reactive oxidizing species ${ }^{\mathrm{a}}$.

\begin{tabular}{lll}
\hline Reactive oxidizing species & Second-order-rate constant $\left(\mathrm{M}^{-1} \mathrm{~s}^{-1}\right)$ & Reference \\
\hline Singlet oxygen $\left({ }^{1} \mathrm{O}_{2}\right)$ & $(3.2 \pm 0.2) \times 10^{6}$ & {$[19]$} \\
Hydroxyl radical $(\mathrm{HO} \bullet)$ & $\mathrm{b}(8.34 \pm 0.25) \times 10^{9}$ & {$[19]$} \\
& $\mathrm{c}(8.92 \pm 0.22) \times 10^{9}$ & {$[25]$} \\
Carbonate radical $\left(\mathrm{CO}_{3}{ }^{*}\right)$ & $3.47 \times 10^{7}$ & {$[32]$} \\
Permanganate $\left(\mathrm{KMnO}_{4}\right)$ & $<1.6 \pm 0.1$ & {$[22]$} \\
Ferrate $\left(\mathrm{K}_{2} \mathrm{FeO}_{4}\right)$ & $(2.5 \pm 2.1) \times 10^{1} \sim(1.6 \pm 0.2) \times 10^{3}$ & {$[24]$} \\
Ozone $\left(\mathrm{O}_{3}\right)$ & $2.7 \times 10^{5}$ & {$[25]$} \\
Free chlorine $\left(\mathrm{HOCl}^{5}\right)$ & $5.6 \times 10^{1}$ & {$[27]$} \\
Sulfate radical $\left(\mathrm{SO}_{4}{ }^{--}\right)$ & ${ }^{\mathrm{d}}(7.71 \pm 0.29) \times 10^{9}$ & {$[32]$} \\
& $\mathrm{e}(5.85 \pm 0.13) \times 10^{9}$ & {$[32]$} \\
\hline
\end{tabular}

${ }^{a}$ Most of the second-order-rate constant was measured by competition kinetics method unless otherwise stated. ${ }^{\mathrm{b}}$ Determined using radical product build up via transient absorption spectroscopy. ${ }^{\mathrm{c}}$ Evaluated by competition kinetics method. ${ }^{\mathrm{d}}$ For $\mathrm{pH}$ 6.0. ${ }^{\mathrm{e}}$ For $\mathrm{pH} 9.0$. 


\section{Figure captions}

Fig. 1. Molecular structure of trimethoprim (TMP) and its substructural analogs, 2,4-diamino-pyrimidine (DAPD) (dash line box) and 1,2,3-trimethoxybenzene (TMBz) (solid line box). $\mathrm{p} K_{\text {as }}$ of TMP were adopted from references [22,25].

Fig. 2. Effects of temperature on TMP degradation by heat-activated PS oxidation. Experimental conditions: $[\mathrm{TMP}]_{0}=30 \mu \mathrm{M},[\mathrm{PS}]_{0}=2 \mathrm{mM}, \mathrm{pH}=7.0, T=50-65{ }^{\circ} \mathrm{C}$. Error bars represent $95 \%$ confidence intervals of replicates $(n=2)$.

Fig. 3. Effects of $\mathrm{pH}$ on the pseudo-first-order rate constants of TMP degradation by thermo-activated PS oxidation. Experimental conditions: $[\mathrm{TMP}]_{0}=30 \mu \mathrm{M},[\mathrm{PS}]_{0}=2 \mathrm{mM}, \mathrm{pH}=$ 7.0, $T=55^{\circ} \mathrm{C}$. Error bars represent $95 \%$ confidence intervals of replicates $(\mathrm{n}=2)$.

Fig. 4. Comparison of TMP degradation with substructural analogs: 2,4-diaminopyrimidine (DAPD) and 1,2,3-trimethoxybenzene (TMBz). Experimental conditions: [Substance $]_{0}=30 \mu \mathrm{M}$, $[\mathrm{PS}]_{0}=2 \mathrm{mM}, \mathrm{pH}=7.0, T=50^{\circ} \mathrm{C}$. Error bars represent $95 \%$ confidence intervals of replicates (n $=2)$.

Fig. 5. Product ion scan mass spectrum for identification of TMP transformation products with $\mathrm{m} / \mathrm{z}$ 323. Precursor ion: $[\mathrm{M}+\mathrm{H}]^{+}=m / z 323$, fragmentor voltage: $120 \mathrm{~V}$, and collision energy: $12 \mathrm{eV}$ for $\mathrm{m} / \mathrm{z}$ 323-1 $(\mathrm{RT}=7.2 \mathrm{~min})$, and $20 \mathrm{eV}$ for $\mathrm{m} / z$ 323-2 $(\mathrm{RT}=9.0 \mathrm{~min})$ and $\mathrm{m} / \mathrm{z} 323-3(\mathrm{RT}=17.5$ $\min )$.

Fig. 6. Time-dependent evolution of TMP transformation products during thermo-activated PS oxidation process. (a) products $m / z 307(\mathrm{TPM}-\mathrm{OH})$ and $\mathrm{m} / \mathrm{z} 305$ (TMP=O); and (b) products $\mathrm{m} / \mathrm{z}$ 323 (three isomers labeled as $m / z 323-1, m / z 323-2$, and $m / z 323-3$, respectively).

Fig. 7. Proposed transformation pathways for TMP degradation in thermo-activated PS oxidation process.

Fig. 8. Effects of water matrix on TMP degradation by thermo-activated persulfate oxidation process. SRW: synthesized river water comprised of $5 \mathrm{mM} \mathrm{HCO}_{3}{ }^{-}$and $2.5 \mathrm{mg} \mathrm{L}^{-1}$ SRFA. SSW: synthesized sea water comprised of $540 \mathrm{mM} \mathrm{Cl}^{-}$and $0.08 \mathrm{mM} \mathrm{Br}$. Experimental conditions: $[\mathrm{TMP}]_{0}=30 \mu \mathrm{M},[\mathrm{PS}]_{0}=2 \mathrm{mM}, \mathrm{pH}=7.0, T=60^{\circ} \mathrm{C}$. Error bars represent $95 \%$ confidence intervals of replicates $(n=2)$. 
Fig. 1.

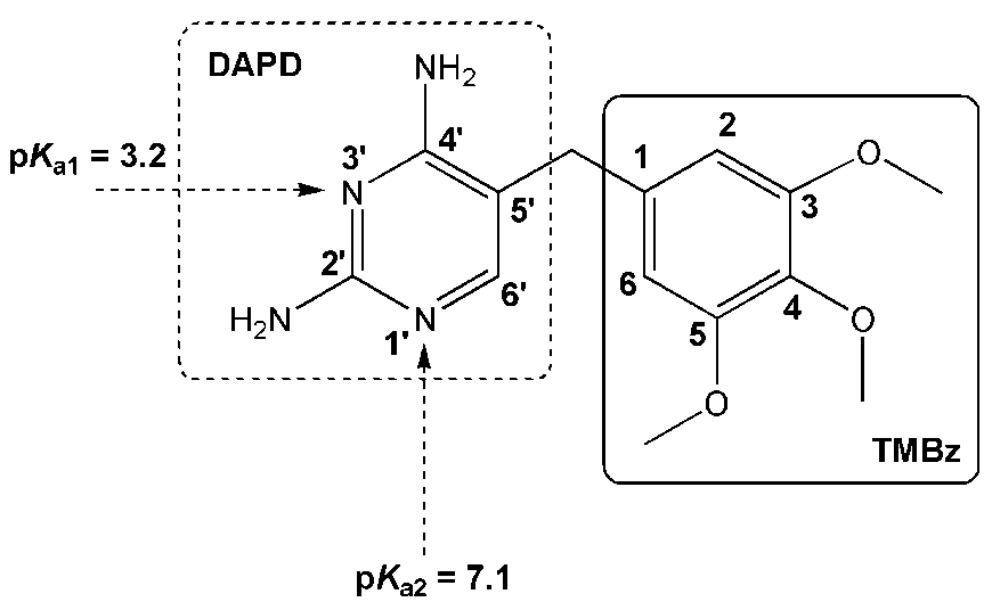


Fig. 2.

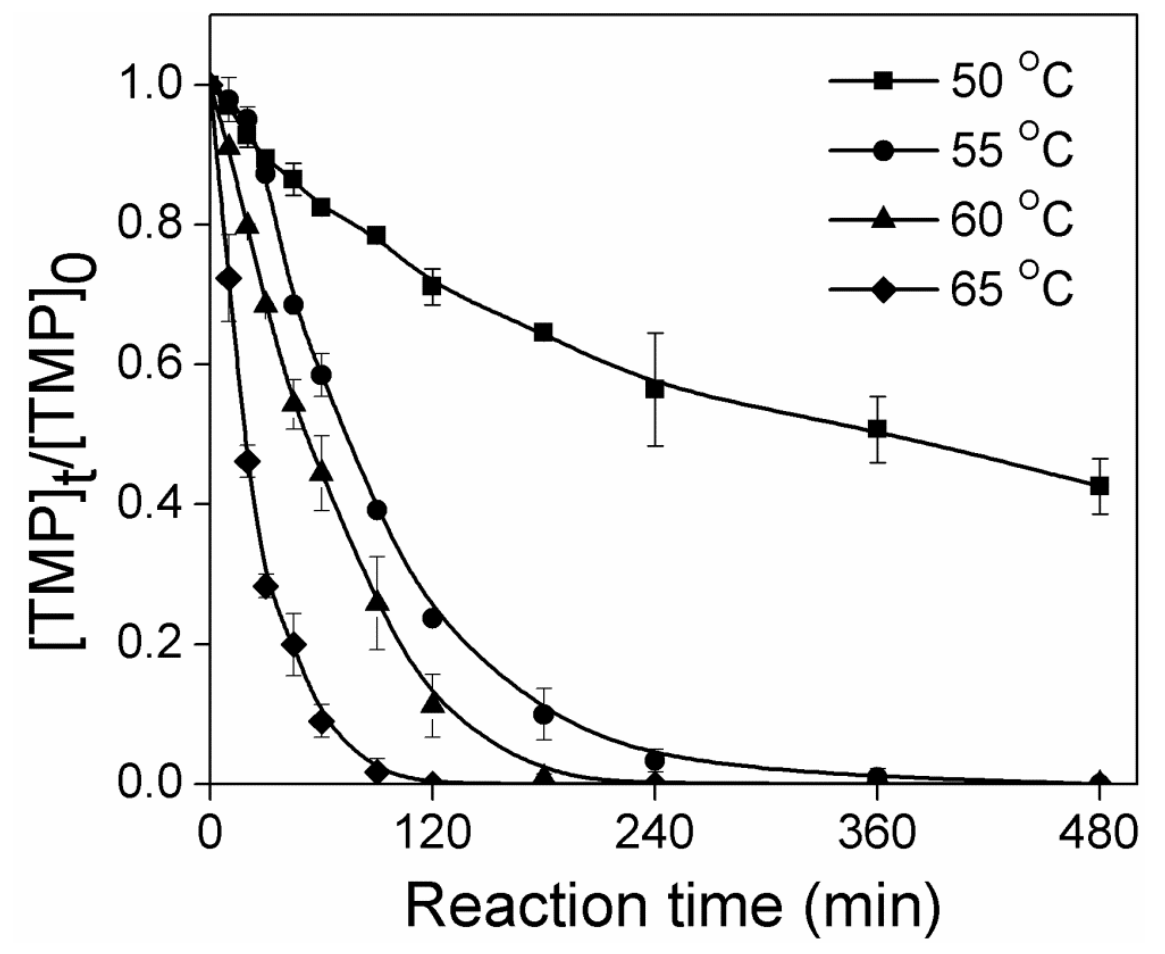


Fig. 3.

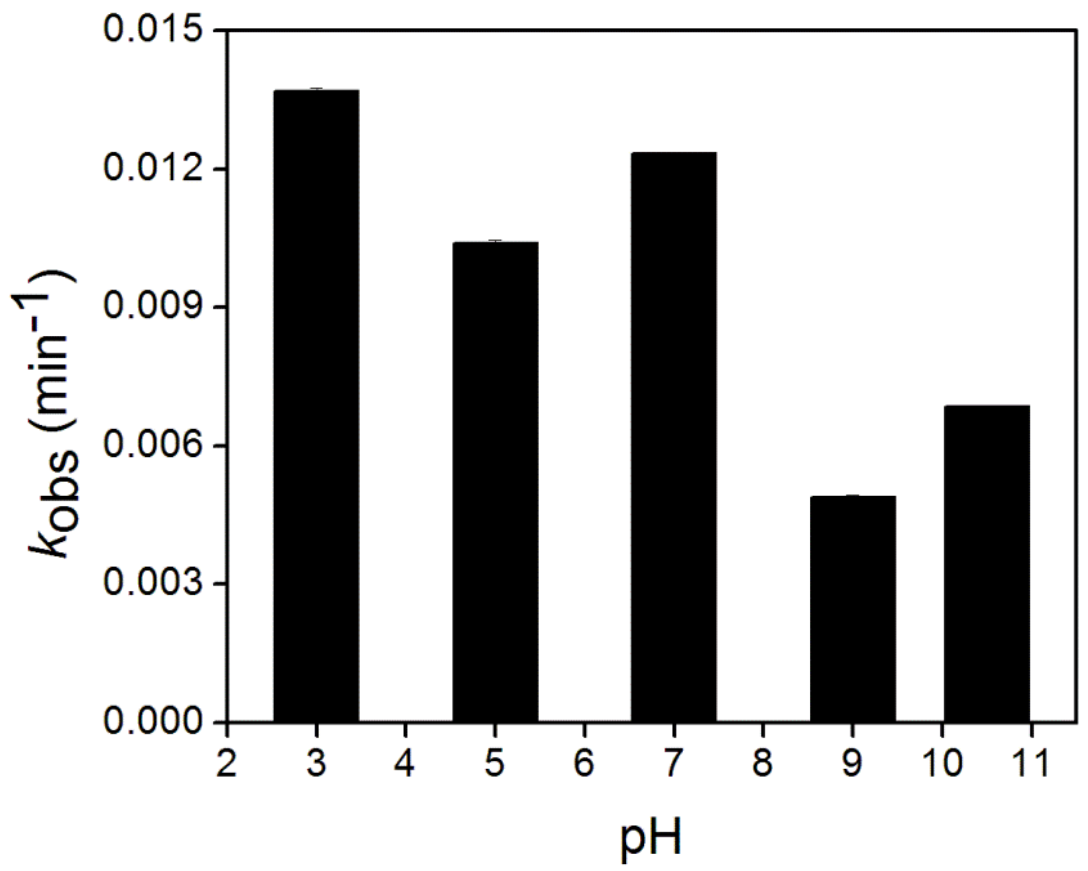


Fig. 4.

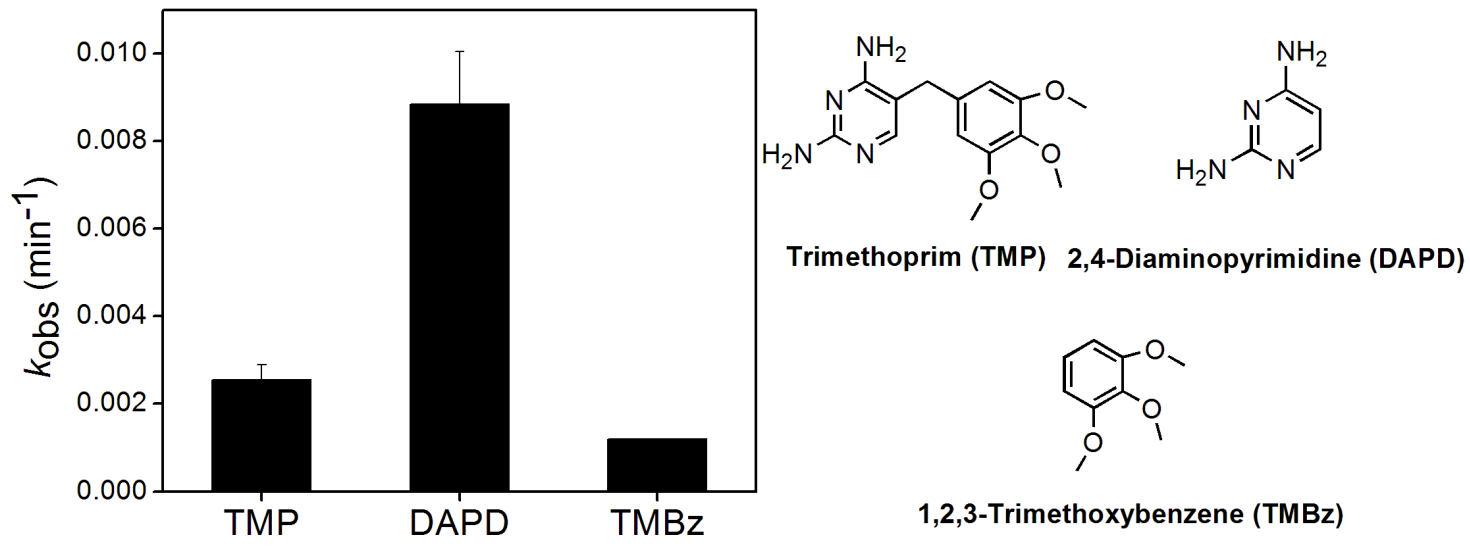


Fig. 5.
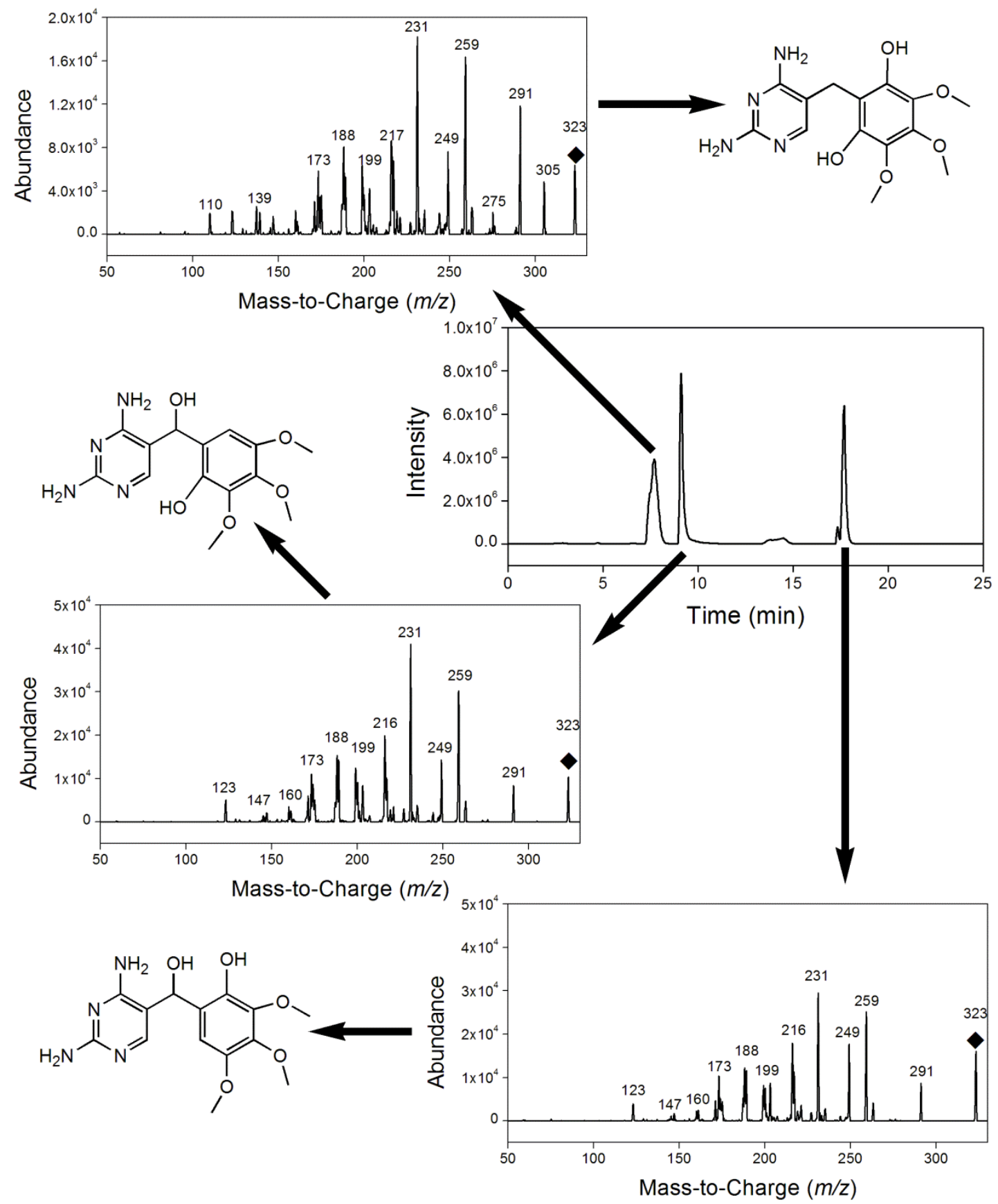
Fig. 6.
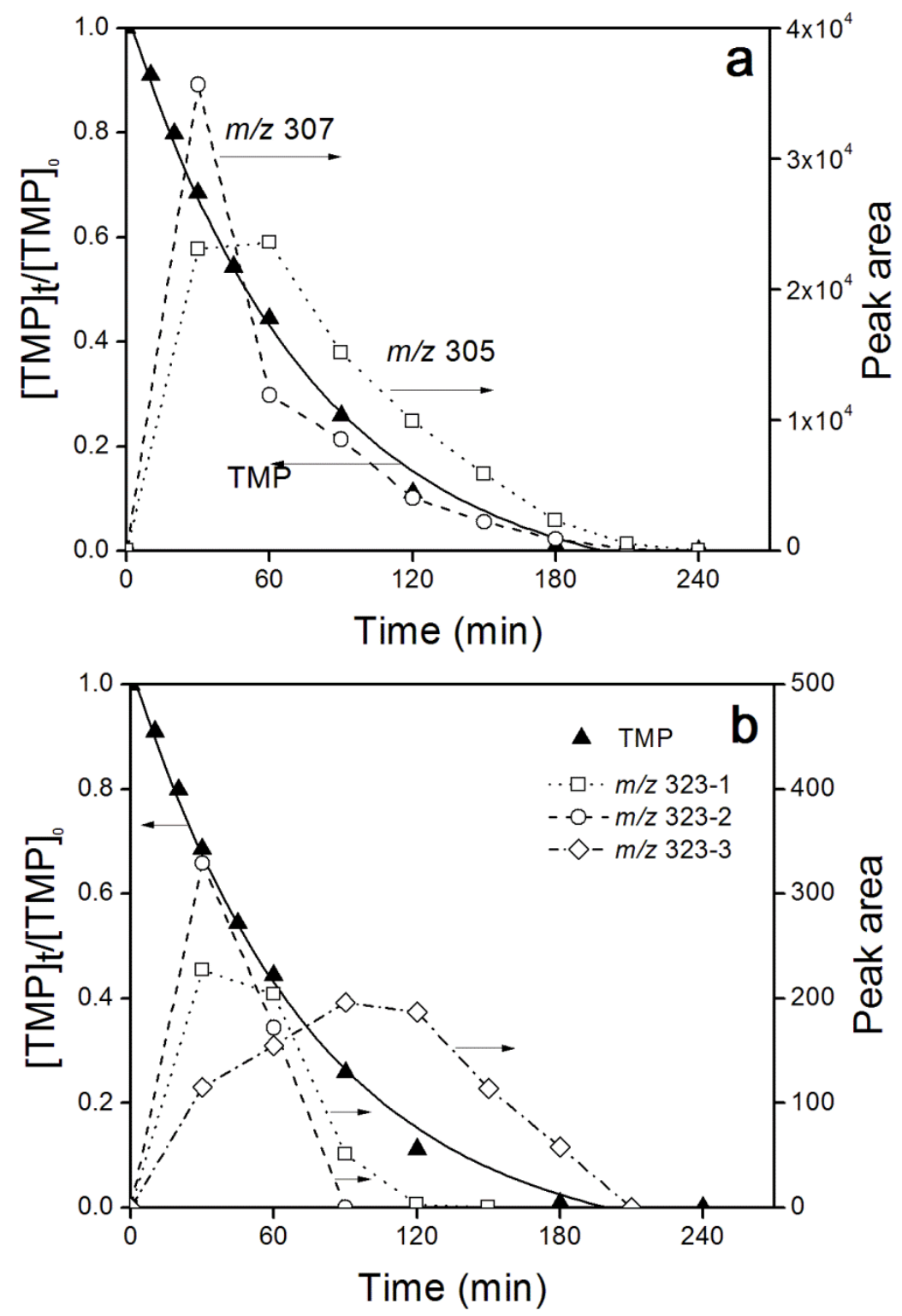
Fig. 7.

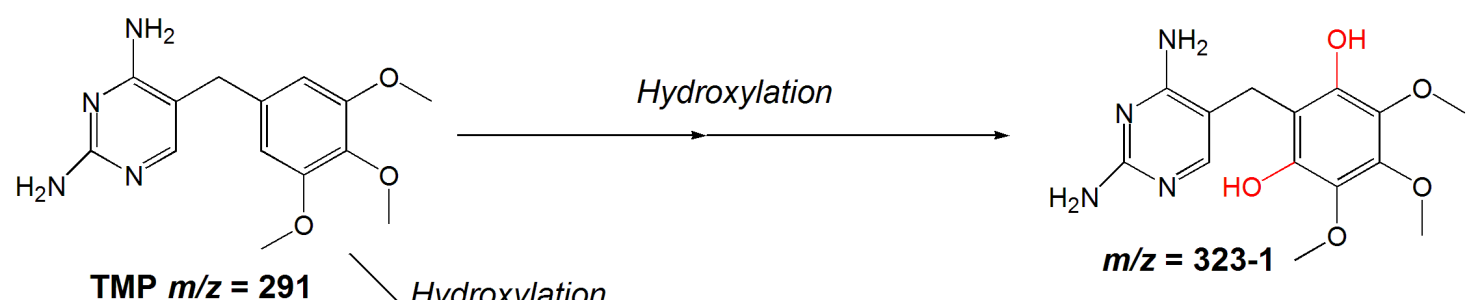

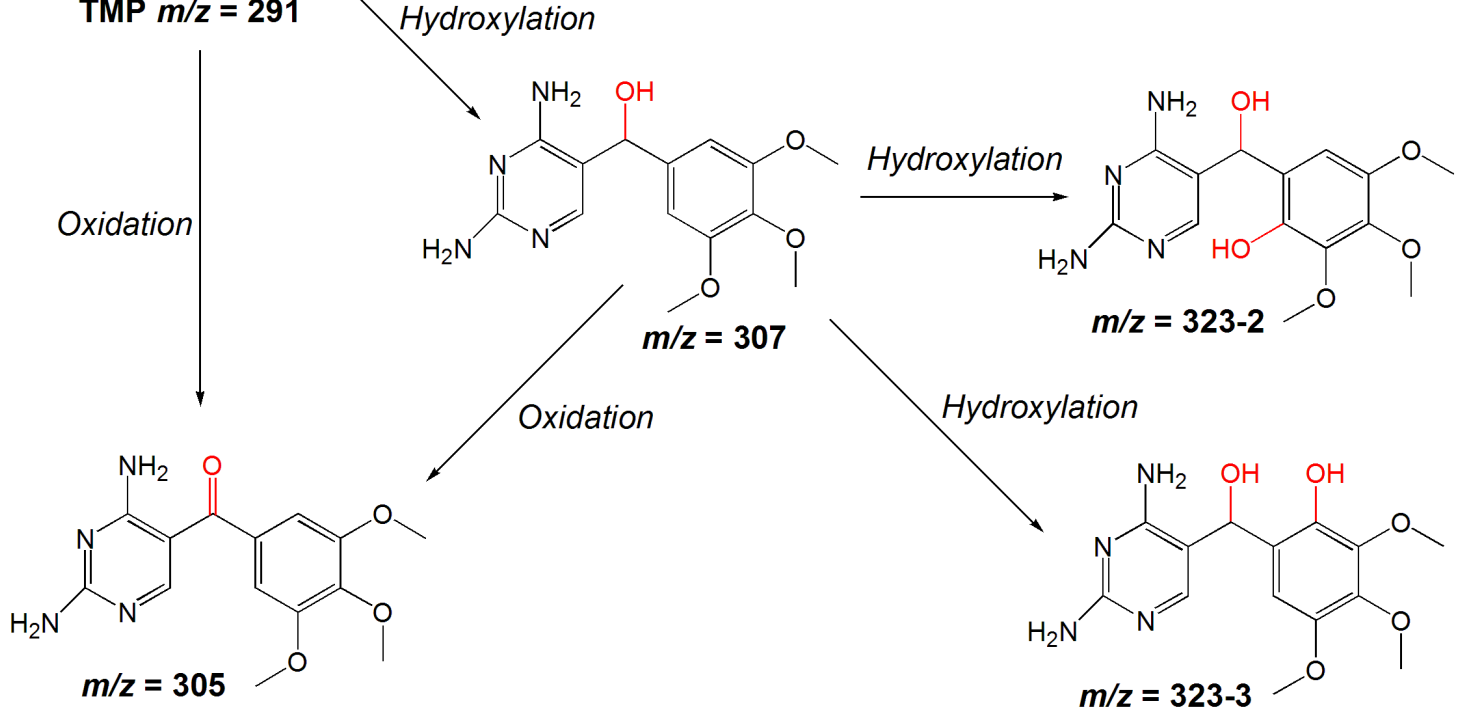


Fig. 8.




Graphic abstract
